\title{
Are we failing to meet the healthcare needs of prisoners with dementia?
}

Authors: Dr Kirsten J. Moore ${ }^{1} \&$ Dr James Burtonwood ${ }^{2,3}$

${ }^{1}$ Marie Curie Palliative Care Research Department, UCL, London UK

${ }^{2}$ Specialty Doctor in Palliative Medicine, University Hospitals Bristol NHS Foundation Trust

${ }^{3}$ GP Partner with Special Interest in Supportive and Palliative Care, Portishead Medical Group

As the population ages, the prevalence of dementia is rapidly increasing. Within the prison system, these demographic changes are also occurring. Socio-economic inequalities, poorer health and lower life expectancy mean age related diseases occur earlier in prisoners compared to the agematched, non-incarcerated population (Cloyes et al., 2015, Rothman et al., 2018). These factors are likely to result in high rates of dementia in prison, however, dementia prevalence is not well documented and may be poorly identified in correctional facilities (Brooke et al., 2018). Currently, in England only 147 prisoners are recorded as having a diagnosis of dementia (NHS England, 2019).

Recognition of prisoners with cognitive impairment can be challenging. Lack of variation in day to day activities and rigid routines might allow better compensation for cognitive impairment and reduce the outward signs of dementia (Ginn, 2012). A mistrust of prison healthcare staff or limited access to healthcare services could delay diagnosis. Where dementia manifests as lack of conformity, resistance or challenging behaviour, deficiencies in staff training or awareness may mean this is viewed as misdemeanour rather than recognised as cognitive impairment (Health and Social Care Committee, 2018).

Thus, most estimates of dementia prevalence behind bars are likely to under-represent the true figure. For example, the Prison and Probation Ombudsman (PPO) of England and Wales has 
previously noted that $4 \%$ of patients dying behind bars had a diagnosis of dementia but that this was likely to be a conservative estimate (Prisons and Probation Ombudsman, 2017). Robust mechanisms for epidemiological purposes in prison are often lacking, relying instead on retrospective analysis of healthcare data. The quality of such data is contingent on the effectiveness of the healthcare consultation as a tool to detect dementia but also the frequency of consultations. In the UK, for example, prison recommendations are that a prisoner has health screening at incarceration yet this may not routinely occur resulting in an incomplete data set from which to produce national demographics (Health and Social Care Committee, 2018).

In 1990, the United Nations Human Rights Office of the High Commissioner established basic principles for the treatment of prisoners including that "Prisoners shall have access to the health services available in the country without discrimination on the grounds of their legal situation". Although increasing attention has been given to the scale of the problem and methods to address it in the general, non-incarcerated population, little research exists within imprisoned populations. Previous publications in International Psychogeriatrics have highlighted the mental health needs of older prisoners (Baidawi, 2016) and older remand prisoners (Davoren et al., 2015) but what are the best ways to support and care for prisoners at risk of developing dementia or who have developed dementia? These questions were explored in a scoping review undertaken in this volume by du Toit and colleagues (2019).

Their review identified a lack of support and services for older prisoners and those with dementia (du Toit et al., 2019). A number of recommendations were made based on the findings from the review. Given that prisoners may lack insight into their cognitive impairment or may be reluctant to report them, screening for cognitive impairment for older prisoners was recommended on a regular basis and on admission. Given the recognised demographic differences between incarcerated and non-incarcerated populations, Du Toit and colleagues suggest screening for age related conditions 
such as dementia at the comparatively young age of 50 or 60 years of age (Cloyes et al., 2015, Rothman et al., 2018).

Screening for dementia would not be without its challenges. There are difficulties in accessing specialists to undertake dementia assessments in the prison setting. Clinicians working in prisons and prison officers need training to undertake basic cognitive screening to identify those who may require specialist assessment. To our knowledge, there are no dementia screening tools which have been validated in a prison setting. To further complicate the challenge screening would need to take into account the high rates of learning disability and low literacy amongst prisoners (Loucks, 2007, Prison Reform Trust, 2017).

Screening would need careful consideration to ensure a diagnosis of dementia did not have unintentional adverse effects. Significant levels of distrust have been found to exist amongst prisoners towards healthcare providers and so an ostensibly well-intentioned screening programme may adversely affect the therapeutic relationship between prisoner and staff (Howerton et al., 2007). The potential of being diagnosed with a mental illness carries significant fear amongst prisoners and may reduce future health-seeking behavior (Howerton et al., 2007). In our clinical experience, a new diagnosis or treatment may have unintended consequences, including loss of social contacts or perks. For example, a prisoner started on a new treatment may be involuntarily moved from the support of their cell-mates to a wing where medical or social care can be better delivered (Burtonwood and Forbes, 2019c, Burtonwood and Forbes, 2019a).

The ethical issues surrounding screening for dementia are also complex. Ensuring that consent is given freely by an incarcerated individual (who may also have dementia) is challenging. Low literacy levels and high rates of learning disabilities would mean that provision of information and checking of understanding would have to be scrupulous to ensure informed consent had been obtained 
(Loucks, 2007, Prison Reform Trust, 2017). In order to be ethically viable, the benefits to the prisoner would have to be significant and unequivocal. At the moment, care for patients with dementia in prison appears to be lacking. Although screening would bring much-needed attention to the issue and clarity to the scale of the problem, there are significant ethical challenges to overcome. Possibly the priority is to improve care pathways for those with known dementia so that the benefits of screening become clearer. Indeed, Du Toit and colleagues (2019) go on to explore some of the alternative approaches.

Training of prison staff, clinicians and prisoners was also recommended in the review to improve the care of prisoners with dementia. Studies in community settings such as residential aged care, indicate that residents with advanced dementia have long term symptoms of pain and agitation indicating that even in environments developed for people with dementia, access to specialist support can be lacking (Sampson et al., 2018). Providing an individualised approach to care in a prison context appears a much greater challenge than in residential care. A number of strategies have been proposed in the literature to tackle this. Penrod et al have described a novel programme aimed at prison security staff who have daily contact with prisoners and are well-placed but often untrained to spot the telltale signs of declining health (Penrod et al., 2016). Through action research, an aide-memoire was developed to assess for changes in memory, grooming and increasing social isolation; symptoms often seen in dementia. Although developed to identify prisoners approaching end of life, such an approach may also prove valuable in identifying prisoners with dementia. Training younger prisoners was an innovative approach identified in the review that can benefit both the younger prisoner and the person with dementia. These interventions need to be implemented with support and training for the younger prisoner and careful selection and supervision of prisoners. 
The lack of suitability of the physical prison environment was another theme in the review (du Toit et al., 2019). Again, these challenges occur in the residential aged care context (Moore et al., 2011). As the Prison and Probation Ombudsman of England and Wales notes: "the prison estate was designed for young, fit men and not for its current ageing population" (Prisons and Probation Ombudsman, 2017). The review identified potential benefits of having separate, specialised units for prisoners with dementia. Again, this is not often available and has cost implications, but the comparative cost of retrofitting and modifying existing prison environments need to be examined. This needs to be balanced with the potential risk of moving prisoners away from family and disturbing routines which can be particularly unsettling for people with dementia. There are simple environmental modifications that can be low cost but aid in orientation and reduce anxiety. The prison environment may also be key to reducing the future burden of dementia. For example, smoking cessation programmes may be an important public health measure to reducing the rates of dementia in younger generations of prisoners.

Where appropriate, helping prisoners maintain family contacts may be an inexpensive yet beneficial intervention. It is rarely possible for a prisoner to receive calls and so maintaining contact with the outside world is contingent on a prisoner's ability to organise permission to make outgoing calls; which may be difficult for a prisoner with dementia. Assistance from family liaison officers or chaplaincy staff may help to reduce social isolation which can be especially detrimental to those with dementia.

Parole or early release of prisoners with dementia was also recommended in the review, but again there were obstacles including finding suitable alternative accommodation and establishing risk assessment protocols. Many countries have mechanisms whereby prisoners approaching the end of life can be considered for early release on compassionate grounds. Dementia is a life-limiting illness yet the practicalities of early release of prisoners with dementia are complex. This may be partly due 
to the fact dementia may go unrecognised as a life-limiting condition and partly because the prognosis and trajectory may be too difficult to predict (Iacobucci, 2019). Of 48 prisoners released on compassionate grounds near the end of life over the last 5 years in England and Wales, none included dementia as the primary reason for release (Burtonwood and Forbes, 2019b).

Recommendations from the review, however, need to be considered with caution. Du Toit and colleagues (2019)acknowledged the dearth of robust research in these settings and so undertook a scoping review, a preferred approach in emerging research areas, incorporating grey literature, commentaries and opinion pieces. Only five of the 35 papers included were based on empirical research including four qualitative studies. Of these five studies, findings included that prisoners did not seek help for cognitive difficulties and that peer support or buddy systems for older prisoners could provide a positive role for both the older prisoner and the peer supporter. With the exception of one conference paper from Malaysia, the remaining 34 papers were from Europe, North America and Australia showing a lack of literature in low and middle income countries. As the review was limited to English language papers, however, there may work in this area that was excluded.

Research into dementia is considerably underfunded compared with other life limiting conditions. The ratio of publications on neurodegenerative disorders compared with articles on cancer is only 1:12 (Alzheimer's Disease International, 2018). In the UK for every $f 10$ spent on health and social care for patients with cancer, $f 1.08$ is invested in research compared with only $f 0.08$ in research on dementia (Luengo-Fernandez et al., 2015). A similar picture occurs in the prison context with low levels of research funding from national health research bodies with approximately $0.1 \%$ of health research finding in North America focusing on health in the criminal justice system (Ahalt et al., 2015). 
Consistent with low levels of research funding, there are many obstacles to conducting research in these vulnerable populations. Qualitative research methods amongst prisoner cohorts can take years longer than similar studies in the non-incarcerated population (Wakai et al., 2009), partly as a result of the additional ethical checks and balances needed for this vulnerable population. The Declaration of Helsinki indicates that medical research should only involve vulnerable groups if the research relates to their health needs and cannot be conducted in a non-vulnerable group. Ethical guidelines and Acts such as the UK's Mental Capacity Act (2005) provide a framework for enabling vulnerable groups to participate and benefit from research. To provide appropriate dementia care to prisoners it is vital that research is conducted in these populations to develop an understanding of effective interventions in this unique context. Without improved research and funding to improve the care of prisoners with dementia, we are breaching the human rights set out by the United Nations to offer access to health services without discrimination.

\section{References (Harvard)}

Ahalt, C., Bolano, M., Wang, E. A. \& Williams, B. 2015. The state of research funding from the National Institutes of Health for criminal justice health research. Ann Intern Med, 162, 34552. doi: $10.7326 / \mathrm{m} 14-2161$

Alzheimer's Disease International 2018. World Alzheimer Report 2018: The state of the art of dementia research: New frontiers London: Alzheimer's Disease International.

Baidawi, S. 2016. Older prisoners: psychological distress and associations with mental health history, cognitive functioning, socio-demographic, and criminal justice factors. Int Psychogeriatr, 28, 385-95. doi: 10.1017/s1041610215001878

Brooke, J., Diaz-Gil, A. \& Jackson, D. 2018. The impact of dementia in the prison setting: A systematic review. Dementia (London), 1471301218801715. doi: 10.1177/1471301218801715 
Burtonwood, J. \& Forbes, K. Defining the Need for Palliative Care Amongst Prisoners in England and Wales. 16th World Congress of the European Association for Palliative Care, 2019a Berlin. 66.

Burtonwood, J. \& Forbes, K. 2019b. Early release rules for prisoners at end of life need reform. BMJ Opinion. doi:

Burtonwood, J. \& Forbes, K. What are the Challenges in Providing Palliative Care for Prisoners in England and Wales? 16th World Congress of the European Association for Palliative Care, 2019c Berlin.

Cloyes, K. G., Berry, P. H., Martz, K. \& Supiano, K. 2015. Characteristics of Prison Hospice Patients: Medical History, Hospice Care, and End-of-Life Symptom Prevalence. Journal of Correctional Health Care, 21, 298-308. doi: https://dx.doi.org/10.1177/1078345815588842

Davoren, M., Fitzpatrick, M., Caddow, F., Caddow, M., O'Neill, C., O'Neill, H. \& Kennedy, H. G. 2015. Older men and older women remand prisoners: mental illness, physical illness, offending patterns and needs. Int Psychogeriatr, 27, 747-55. doi: 10.1017/s1041610214002348

du Toit, S., Withall, A., O'Loughlin, K., Nikola Ninaus , N., Lovarini, M., Snoyman, P., Butler, T., Forsyth, K. \& Surr, C. 2019. Best care options for older prisoners with dementia - a scoping review. International Psychogeriatrics, (in press). doi:

Ginn, S. 2012. Elderly prisoners. Bmj, 345, e6263. doi: 10.1136/bmj.e6263

Health and Social Care Committee 2018. Prison Health: Twelfth Report of Session 2017-2019. In: House of Commons (ed.). London.

Howerton, A., Byng, R., Campbell, J., Hess, D., Owens, C. \& Aitken, P. 2007. Understanding help seeking behaviour among male offenders: qualitative interview study. BMJ, 334, 303. doi: 10.1136/bmj.39059.594444.AE

lacobucci, G. 2019. Early release rules for prisoners at end of life may be "discriminatory," say doctors. Bmj, 365, 14140. doi: 10.1136/bmj.14140 
Loucks, N. 2007. No One Knows: Identifying and Supporting Prisoners with Learning Difficulties and Learning Disabilities: The prevalence and associated needs of offenders with learning difficulties and learning disabilities. Prison Reform Trust.

Luengo-Fernandez, R., Leal, J. \& Gray, A. 2015. UK research spend in 2008 and 2012: comparing stroke, cancer, coronary heart disease and dementia. BMJ Open, 5, e006648. doi: 10.1136/bmjopen-2014-006648

Moore, K. J., Hill, K. D., Robinson, A. L., Haines, T. P., Haralambous, B. \& Nitz, J. C. 2011. The state of physical environments in Australian residential aged care facilities. Aust Health Rev, 35, 4127. doi: $10.1071 /$ ah10932

NHS England 2019. Response to freedom of Information request (Ref: FOI-059430).

Penrod, J., Loeb, S. J., Ladonne, R. A. \& Martin, L. M. 2016. Empowering Change Agents in Hierarchical Organizations: Participatory Action Research in Prisons. Research in Nursing \& Health, 39, 142-53. doi: https://dx.doi.org/10.1002/nur.21716

Prison Reform Trust 2017. Bromley Briefings Prison Factfile Autumn 2017. Prison Reform Trust,. Prisons and Probation Ombudsman. 2017. Learning from PPO Investigations: Older Prisoners [Online]. Available: https://s3-eu-west-2.amazonaws.com/ppo-dev-storage4dvljl6iafyh/uploads/2017/06/6-3460 PPO Older-Prisoners WEB.pdf [Accessed 5/7/2019].

Rothman, A., McConville, S., Hsia, R., Metzger, L., Ahalt, C. \& Williams, B. A. 2018. Differences between incarcerated and non-incarcerated patients who die in community hospitals highlight the need for palliative care services for seriously ill prisoners in correctional facilities and in community hospitals: A cross-sectional study. Palliat Med, 32, 17-22. doi: $10.1177 / 0269216317731547$

Sampson, E. L., Candy, B., Davis, S., Gola, A. B., Harrington, J., King, M., Kupeli, N., Leavey, G., Moore, K., Nazareth, I., Omar, R. Z., Vickerstaff, V. \& Jones, L. 2018. Living and dying with advanced dementia: A prospective cohort study of symptoms, service use and care at the end of life. Palliat Med, 32, 668-681. doi: 10.1177/0269216317726443 
Wakai, S., Shelton, D., Trestman, R. \& Kesten, K. 2009. Conducting Research in Corrections:

Challenges and Solutions. Behav. Sci. Law 27, 743-752. doi: 10.1002/bsl.894 